\title{
Alcohol, metabolic risk and elevated serum gamma-glutamyl transferase (GGT) in Indigenous Australians
}

\author{
Matthew T Haren ${ }^{1,2,3^{*}}$, Ming Li $i^{3}$, John Petkov ${ }^{2,4}$, Robyn A McDermott ${ }^{3}$
}

\begin{abstract}
Background: The interaction between overweight/obesity and alcohol intake on liver enzyme concentrations have been demonstrated. No studies have yet examined the interaction between metabolic syndrome or multiple metabolic risk factors and alcohol intake on liver enzymes. The aim of this study was to examine if alcohol consumption modifies the effect of metabolic risk on elevated serum GGT in Indigenous Australians.

Methods: Data were from N = 2609 Indigenous Australians who participated in a health screening program in rural far north Queensland in 1999-2000 (44.5\% response rate). The individual and interactive effects of metabolic risk and alcohol drinking on elevated serum GGT concentrations ( $\geq 50 \mathrm{U} / \mathrm{L}$ ) were analyzed using logistic regression.

Results: Overall, 26\% of the population had GGT $\geq 50$ U/L. Elevated GGT was associated with alcohol drinking (moderate drinking: OR 2.3 [95\% 1.6 - 3.2]; risky drinking: OR 6.0 [4.4 - 8.2]), and with abdominal obesity (OR 3.7 [2.5 - 5.6]), adverse metabolic risk cluster profile (OR 3.4 [2.6 - 4.3]) and metabolic syndrome (OR 2.7 [2.1 - 3.5]) after adjustment for age, sex, ethnicity, smoking, physical activity and BMI. The associations of obesity and metabolic syndrome with elevated GGT were similar across alcohol drinking strata, but the association of an adverse metabolic risk cluster profile with elevated GGT was larger in risky drinkers (OR 4.9 [3.7 - 6.7]) than in moderate drinkers (OR 2.8 [1.6 - 4.9]) and abstainers (OR 1.6 [0.9 - 2.8]).

Conclusions: In this Indigenous population, an adverse metabolic profile conferred three times the risk of elevated GGT in risky drinkers compared with abstainers, independent of sex and ethnicity. Community interventions need to target both determinants of the population's metabolic status and alcohol consumption to reduce the risk of elevated GGT.
\end{abstract}

\section{Background}

Non-alcoholic fatty liver disease (NAFLD) has become the most common cause of chronic liver disease and cryptogenic cirrhosis in developed countries. The increasing prevalence of obesity, type 2 diabetes, and metabolic syndrome may be important drivers of increasing rates of NAFLD diagnoses [1]. An elevated serum gamma-glutamyl transferase (GGT) has been demonstrated as a biomarker of NAFLD [2] and, although it is not the only marker of chronic liver disease, it does predict future diabetes, coronary heart disease and stroke $[3,4]$.

\footnotetext{
* Correspondence: Matt.Haren@unisa.edu.au

'Spencer Gulf Rural Health School (SGRHS), University of South Australia and The University of Adelaide, Whyalla Norrie SA, Australia
}

The Australian indigenous population has an excess of metabolic syndrome and type 2 diabetes relative to the non-indigenous population [5-7]. BMI-specific incidence rates for type 2 diabetes in Australian Aboriginal adults are among the highest in the world [8]. The overall incidence rate in rural Far North Queensland indigenous communities from 2000 to 2006 was 29 per 1000 person years (predicted to equate to 120 new diabetes diagnoses per year) [9]. Diabetes and CVD account for 7\% and $14 \%$, respectively of the overall burden of disease in Indigenous Australians, and for $12 \%$ and $24 \%$ respectively, of the health gap between indigenous and nonindigenous Australians [10].

Heavy and moderate drinkers are more likely to have elevated serum GGT when compared to abstainers [11]. The metabolic effects of alcohol include an increase in 
conversion of acetyl CoA to triglycerides (TG) which are secreted into the blood as very low density lipoproteins (VLDLs); ectopic fat accumulation in the liver from excess TG production and a rise in GGT and other liver enzymes; and weight gain from energy derived from alcohol (about $29 \mathrm{kj} / \mathrm{gram}$ ) [12]. Alcohol accounted for $5 \%$ of the total Indigenous burden of disease, similar to high cholesterol and blood pressure, and for $4 \%$ in the health gap with non-indigenous Australians [10].

Li et al. reported elevated GGT with obesity, metabolic syndrome and physical inactivity in Indigenous non-drinkers in this cohort [13]. Little work has been published on NAFLD or alcohol-related liver disease in Indigenous populations worldwide. It is not known whether the additive effects of body fatness and alcohol intake on serum liver enzymes described in Nordic populations [14,15] apply to Indigenous Australians or whether drinking combined with multiple metabolic risk factors (or metabolic syndrome) further increases risk of elevated liver enzymes.

Evidence suggests that Aboriginal people have a greater risk of coronary heart disease events than would be expected based on Framingham risk functions [16]. Similar underestimation of risk using these algorithms has been reported in ethnic minorities in the UK [17] with overestimated risk in other ethnic groups $[18,19]$. Moreover, normative values for waist circumference have not been established for Aboriginal and Torres Strait Islanders (TSI) and these populations differ in a number of metabolic characteristics, relative to fatness $[7,20,21]$. Due to this uncertainty, we defined population metabolic profiles using cluster analysis and then compared the alcohol stratified effects of metabolic risk cluster versus International Diabetes Federation (IDF) classified metabolic syndrome on elevated GGT.

\section{Methods}

\section{Population}

Subjects were participants in The Well Person's Health Check [22]. Briefly, in 1999 - 2000, all indigenous residents aged 13 years and older, in 23 far north Queensland rural communities, were invited to participate through printed media, local radio, and word of mouth via the local health service, community council and community groups. A total of 3811 (participation rate 44.5\%) participated in the study. The cohort was demographically representative of the indigenous population of the local area when compared to local population census data. Aboriginal and TSI are recognized as distinct ethnic groups and ascertainment of ethnicity was by self-identification in a manner consistent with Australian national minimum dataset specifications [23]. After exclusion of children under age $15(\mathrm{~N}=496)$, non-indigenous $(\mathrm{N}=482)$ and individuals reporting joint Aboriginal-TSI descent $(\mathrm{N}=224)$, a total of 2609 participants were included in this analysis. All participants provided informed consent to take part in the study. The study procedures were in accordance with the ethical standards on human research and thereby approved by the Cairns Base Hospital Human Research Ethics Committee with support from the peak Indigenous Health Organizations, Apunipima Cape York Health Council and the Torres Strait and Northern Peninsula Area Health Council.

\section{Data Collection}

Height to the nearest 0.1 centimeter $(\mathrm{cm})$ and weight to the nearest 0.1 kilogram $(\mathrm{Kg})$ were measured in participants without shoes and wearing only light clothing. Body mass index (BMI) was calculated (weight $(\mathrm{kg})$ / height $\left(\mathrm{m}^{2}\right)$ ). Waist circumference was measured midway between the lower border of the rib cage and the top of the iliac crest and recorded to the nearest 0.1 centimeter. Data were collected on self-reported medical conditions and none reported known liver disease. Physical activity was measured using a 7-day recall method in which the participants were asked to report daily physical activities of at least moderate intensity, lasting at least 30-minutes, performed during the week before their health check. Physical activity level was defined by American Heart Association criteria in which "active" reflects moderate to vigorous physical activity for at least 30-minutes per day on 5 days in the week before the survey [24]. Smoking behaviour was collected by standard questionnaire. The amount of alcohol consumed over a week was collected by 7-day recall diary and converted to number of standard drinks per week (1 standard drink $=10$ grams of alcohol). Risky alcohol drinking was defined as greater than 6 standard drinks on any occasion or greater than 4 standard drinks per day in the recall week for males and greater than 4 drinks on any occasion or greater than 2 drinks per day in females [22,25].

Three seated blood pressure measurements were taken at 2 minute intervals after 10 minutes rest using a Dinamap automated oscillometric device (Critikon Corporation, USA) and the average was used in all analyses. Venous blood was sampled in the morning after an 8-hour fast as previously described [22]. GGT was measured using the kinetic photometric procedure with Cobas Integra 800 (Roche Diagnostics, USA). Blood glucose and lipids were measured using photometric enzyme endpoint assay with Cobas Integra 700/ 400 (Roche Diagnostics, USA).

The outcome variable, GGT, was classified as normal $(<50 \mathrm{U} / \mathrm{L})$ or elevated $(\geq 50 \mathrm{U} / \mathrm{L})$ based on laboratory specific reference ranges (Queensland Pathology Service, http://www.health.qld.gov.au/qhcss/qhps/default.asp). 
Metabolic syndrome was defined according to the IDF definition of waist circumference (Europid cut-offs: $\geq 94 \mathrm{~cm}$ for men or $\geq 80 \mathrm{~cm}$ for women) plus any two of the following: raised triglycerides $(\geq 1.7 \mathrm{mmol} / \mathrm{L})$; reduced HDL cholesterol $(<1.03 \mathrm{mmol} / \mathrm{L}$ for men or $<1.29 \mathrm{mmol} / \mathrm{L}$ for women); raised blood pressure ( $\geq 130 \mathrm{mmHg}$ for systolic or $\geq 85 \mathrm{mmHg}$ for diastolic); and raised fasting plasma glucose $(\geq 5.6 \mathrm{mmol} / \mathrm{L})$ [26]. Specific treatment for lipid abnormalities or previously diagnosed hypertension and previously diagnosed T2DM were not used in classification.

Waist circumference was used as a continuous variable and also to classify abdominal overweight and obesity, using World Health Organization (WHO) gender-specific criteria: overweight was $\geq 80 \mathrm{~cm}$ in women and $\geq 94 \mathrm{~cm}$ in men; obesity was $\geq 88 \mathrm{~cm}$ in women and $\geq 102 \mathrm{~cm}$ in men; $<80 \mathrm{~cm}$ in women and $<94 \mathrm{~cm}$ in men was classified as normal. BMI was used as a continuous variable and also to classify generalized overweight and obesity: < $25 \mathrm{Kg} / \mathrm{m}^{2}$ (normal); $25-29.9 \mathrm{Kg} / \mathrm{m}^{2}$ (overweight) and $\geq 30 \mathrm{Kg} / \mathrm{m}^{2}$ (obesity) [27]. Diabetes was determined by clinical diagnosis of diabetes, verified by participants' medical records, or 2 hour glucose tolerance test or fasting blood glucose $\geq 7.0 \mathrm{mmol} / \mathrm{L}$ [28]. Blood pressure, fasting triglycerides, total cholesterol, HDL and glucose were used as continuous variables in all analyses.

\section{Derivation of the metabolic risk factor cluster variable (MR cluster)}

Cluster Analysis is the process of assigning members of a population into groups such that the members of each group share common characteristics. The method is an example of unsupervised learning. There is no a priori assumption made about what the groups represent or indeed the number of groups. Expectation Maximisation (EM) cluster analysis was applied to standardized (mean centred) variables: waist circumference, TG, HDL, systolic and diastolic blood pressure and fasting glucose, and was performed in STATISTICA (data analysis software system), version 8.0 (StatSoft, Inc. (2007) http://www. statsoft.com). To determine the major contributing variables to cluster membership, partial least squares (PLS) was applied since the predictors (the original variables) are highly correlated and so ordinary multinomial regression is inaccurate due to multicollinearity. Detail on both EM cluster analysis and PLS can be found in Additional file 1 .

\section{Statistical Analysis}

A priori it was expected that Aboriginal and TSI people would differ significantly in their anthropometric and metabolic characteristics, so comparisons for all variables were made across Aboriginal versus TSI ethnicity. Comparisons were also made for all variables across normal versus elevated GGT. Comparative analyses were by Chi-squared tests for categorical variables, independent t-tests for normally distributed continuous variables or Mann-Whitney rank-sum tests for nonnormally distributed continuous variables. Unadjusted comparisons between MR clusters were analyzed using independent samples t-tests for continuous variables and Chi-squared analysis with Fisher's exact test for categorical variables. Logistic regression models were built to determine the associations (log odds) of drinking, metabolic syndrome and MR cluster with elevated GGT ( $\geq 50 \mathrm{U} / \mathrm{L}$ ) for the whole population and stratified by ethnicity and sex. Similarly, odds ratios for the association of abdominal obesity, BMI categories, metabolic syndrome and MR cluster with elevated GGT, were calculated for the whole population and stratified by drinking status. Separate logistic regression models were built to examine the effect on elevated GGT of interactions between drinking and: sex; ethnicity; overweight and obesity defined by BMI and waist circumference; and metabolic risk defined by IDF MetS criteria and MR cluster. Models were adjusted for age, sex, ethnicity, BMI, smoking and physical activity levels where appropriate. Data analyses were performed using STATA version 10.1 (STATA Corp, College Station, Texas, USA).

\section{Results}

Participants with missing data on serum GGT $(\mathrm{N}=76)$ were not different in age, sex, BMI, metabolic profile or lifestyle behaviours than those with GGT data. Those missing information regarding metabolic syndrome $(\mathrm{N}=$ 224) were not different in age, sex, BMI, and lifestyle behaviours but had lower mean BP than those with complete metabolic syndrome information $(125.5 \pm 18.4$ $\mathrm{v} 130.4 \pm 19.6 \mathrm{mmHg}, \mathrm{P}<0.001)$. Those missing records of drinking $(\mathrm{N}=83)$ tended to be older (43.2 \pm 17.6 v $37.2 \pm 15.3$ years, $\mathrm{P}<0.001)$ and more likely to be female $(65.1 \%$ v $51.4 \%, \mathrm{P}=0.014)$.

Table 1 describes the metabolic and behavioral characteristics of the cohort by Aboriginal and TSI status and sex. In both sexes, the TSI population had a significantly lower prevalence of elevated GGT, a higher prevalence of obesity, type 2 diabetes, metabolic syndrome and physically active people, and a lower proportion of smokers and drinkers, when compared with the Aboriginal population (all Ps $<0.05$ ). Waist circumference, BMI, SBP and fasting glucose were higher and GGT and triglycerides were lower in TSI when compared with Aboriginal people (all Ps $<0.05$ ). The prevalence of adverse MR cluster was significantly greater in TSI when compared to Aboriginal men, but was similar in women.

Table 2 describes the demographic, behavioral and metabolic characteristics of the cohort by normal and 
Table 1 Metabolic and behavioral characteristics of the study population, by ethnicity and sex

\begin{tabular}{|c|c|c|c|c|c|}
\hline & Aboriginal ( $\mathrm{n}$ & & TSI $(n=968)$ & & Overall $(\mathrm{N}=2609)$ \\
\hline & Mean or No. & $95 \% \mathrm{Cl}$ & Mean or No. & $95 \% \mathrm{Cl}$ & Mean or No. \\
\hline Female & $N=881$ & & $N=471$ & & \\
\hline Age, years (SD) & $37.4(15.5)$ & $36.4-38.4$ & $38.3(16.0)$ & $36.9-39.75$ & $37.7(15.7)$ \\
\hline WC, $\mathrm{cm}(\mathrm{SD})$ * & $92.2(16.5)$ & $91.1-93.3$ & $103.6(15.6)$ & $102.1-105.1$ & $96.2(17.4)$ \\
\hline BMI, $\mathrm{kg} / \mathrm{m}^{2}(\mathrm{SD})^{*}$ & $25.5(6.6)$ & $25.2-25.9$ & $31.0(6.7)$ & $30.5-31.4$ & $27.6(7.1)$ \\
\hline SBP, $m m H g(S D)^{*}$ & $125.5(17.0)$ & $124.1-126.9$ & $130.3(16.1)$ & $128.4-132.3$ & $127.2(21.3)$ \\
\hline DBP, $\mathrm{mmHg}(\mathrm{SD})^{*}$ & $69.7(13.5)$ & $68.8-70.6$ & $67.8(12.2)$ & $66.7-68.9$ & $69.0(13.1)$ \\
\hline T Chol, mmol/L (SD) & $4.8(1.0)$ & $4.7-4.82$ & $4.8(1.0)$ & $4.75-4.9$ & $4.8(1.0)$ \\
\hline $\mathrm{HDL}, \mathrm{mmol} / \mathrm{L}(\mathrm{SD})$ * & $1.16(0.3)$ & $1.14-1.18$ & $1.11(0.2)$ & $1.09-1.13$ & $1.1(0.3)$ \\
\hline $\mathrm{GGT}, \mathrm{U} / \mathrm{L}(\mathrm{SD})$ * & $39.2(47.1)$ & $36.0-42.4$ & $27.2(21.1)$ & 25.3-29.1 & $35.0(40.4)$ \\
\hline $\mathrm{FPG}, \mathrm{mmol} / \mathrm{L}(\mathrm{SD})^{*}$ & $5.5(2.5)$ & $5.4-5.7$ & $6.2(3.1)$ & $5.9-6.5$ & $5.8(2.7)$ \\
\hline Trigs, $\mathrm{mmol} / \mathrm{L}(\mathrm{SD}) \ddagger^{*}$ & $1.7(1.2)$ & $1.6-1.73$ & $1.5(1.1)$ & $1.4-1.6$ & $1.6(1.1)$ \\
\hline Abdominal obesity $+(\%)^{*}$ & & & & & \\
\hline Normal & 205 (23.6) & $20.5-26.1$ & $43(9.1)$ & $6.5-11.7$ & $248(18.5)$ \\
\hline Overweight & $158(18.2)$ & $15.4-20.4$ & $40(8.5)$ & $6.0-11.0$ & $198(14.8)$ \\
\hline Obesity & $507(58.3)$ & $55.5-62.1$ & $388(82.4)$ & 78.9-85.8 & $895(66.7)$ \\
\hline BMI $(\%)^{*}$ & & & & & \\
\hline$<25$ & $405(46.0)$ & $42.7-49.3$ & $76(16.1)$ & $12.8-19.5$ & 481 (35.6) \\
\hline $25-30$ & $237(26.9)$ & $24.0-29.8$ & $109(23.1)$ & 19.3-27.0 & $346(25.6)$ \\
\hline $30+$ & $239(27.1)$ & 24.2-30.1 & $286(60.7)$ & $48.8-55.1$ & $525(38.8)$ \\
\hline Smokers (\%)* & $490(56.0)$ & $52.7-59.3$ & $211(44.8)$ & $40.3-49.3$ & $701(52.1)$ \\
\hline Drinking $(\%) *$ & $526(62.4)$ & $59.2-65.7$ & $233(51.1)$ & $46.5-55.7$ & $759(58.5)$ \\
\hline Risky drinking † (\%) * & $356(67.7)$ & 63.7-71.7 & $112(48.1)$ & $41.6-54.5$ & $468(61.7)$ \\
\hline Physically active $†(\%)^{*}$ & 164 (18.6) & $16.0-21.2$ & $117(24.8)$ & 20.9-28.7 & $281(20.8)$ \\
\hline GGT $\geq 50 \mathrm{U} / \mathrm{L}(\%) *$ & $181(21.2)$ & $18.4-23.9$ & $36(7.8)$ & $5.4-10.3$ & $217(16.5)$ \\
\hline Diabetes (\%)* & $114(12.9)$ & $10.7-15.2$ & $107(22.7)$ & $18.9-26.5$ & $221(16.4)$ \\
\hline Metabolic syndrome $+(\%) *$ & $353(40.1)$ & $36.9-43.4$ & $246(52.2)$ & $47.7-56.7$ & $595(44.3)$ \\
\hline Adverse MR cluster profile $†(\%)$ & $268(34.3)$ & $31.0-37.6$ & $171(37.7)$ & $33.2-42.1$ & 439 (35.6) \\
\hline Male & $N=760$ & & $N=497$ & & \\
\hline Age, years $(S D)$ & $36.6(14.9)$ & $35.5-37.7$ & $37.5(15.2)$ & 36.2-38. 9 & $37.0(15.1)$ \\
\hline WC, $\mathrm{cm}(\mathrm{SD})$ * & $89.7(14.6)$ & $88.7-90.8$ & $100.7(15.0)$ & $99.4-102.1$ & $94.1(15.7)$ \\
\hline BMI, $\mathrm{kg} / \mathrm{m}^{2}(\mathrm{SD})^{*}$ & $24.5(5.6)$ & $24.1-24.9$ & $29.8(5.8)$ & $29.2-30.3$ & $26.6(6.2)$ \\
\hline SBP, $\mathrm{mmHg}(\mathbf{S D})^{*}$ & $130.8(19.5)$ & $129.6-132.0$ & $136.3(19.1)$ & $134.8-137.7$ & $130.0(16.9)$ \\
\hline DBP, $\mathrm{mmHg}(\mathrm{SD})$ & $74.2(13.8)$ & $73.2-75.2$ & $73.4(13.1)$ & 72.3-74.6 & $73.9(13.5)$ \\
\hline T Chol, mmol/L (SD)* & $5.0(1.1)$ & 4.9- 5.04 & $5.2(1.0)$ & $5.1-5.3$ & $5.1(1.1)$ \\
\hline $\mathrm{HDL}, \mathrm{mmol} / \mathrm{L}(\mathrm{SD})$ * & $1.2(0.4)$ & $1.17-1.22$ & $1.1(0.3)$ & $1.102-1.15$ & $1.2(0.3)$ \\
\hline $\mathrm{GGT}, \mathrm{U} / \mathrm{L}(\mathrm{SD})$ * & $71.0(85.6)$ & $64.8-77.3$ & $46.0(49.2)$ & $41.6-50.4$ & $61.0(74.2)$ \\
\hline FPG, $\mathrm{mmol} / \mathrm{L}(\mathrm{SD})^{*}$ & $5.4(2.1)$ & $5.2-5.5$ & $6.0(2.8)$ & $5.7-6.2$ & $5.6(2.4)$ \\
\hline Trigs, $\mathrm{mmol} / \mathrm{L}(\mathrm{SD}) \ddagger^{*}$ & $2.1(1.9)$ & $2.0-2.2$ & $1.9(1.4)$ & $1.7-2.0$ & $2.0(1.8)$ \\
\hline Abdominal obesity $+(\%)^{*}$ & & & & & \\
\hline Normal & $486(64.1)$ & $60.5-67.4$ & $156(31.5)$ & $27.3-35.5$ & $642(51.2)$ \\
\hline Overweight & $130(17.2)$ & $14.4-19.9$ & $111(22.4)$ & $18.7-26.0$ & $241(19.2)$ \\
\hline Obesity & $142(18.7)$ & $16.2-21.7$ & $228(46.1)$ & 78.9-85.8 & $370(29.5)$ \\
\hline BMI (\%)* & & & & & \\
\hline$<25$ & $856(52.2)$ & $49.7-54.6$ & $178(18.4)$ & $15.9-20.8$ & $1034(39.6)$ \\
\hline $25-30$ & $417(25.4)$ & $23.3-27.5$ & $287(29.7)$ & $26.8-32.5$ & $704(27.0)$ \\
\hline $30+$ & $368(22.4)$ & $20.4-24.4$ & $503(52.0)$ & $48.8-55.1$ & $871(33.4)$ \\
\hline Smokers (\%)* & $516(68.8)$ & $65.5-72.1$ & $274(55.5)$ & $51.1-59.9$ & $1491(57.6)$ \\
\hline Drinking $(\%) *$ & $607(82.3)$ & $79.5-85.0$ & $369(75.3)$ & 71.5-79.1 & $976(79.5)$ \\
\hline
\end{tabular}


Table 1 Metabolic and behavioral characteristics of the study population, by ethnicity and sex (Continued)

\begin{tabular}{|c|c|c|c|c|c|}
\hline Risky drinking † (\%) * & $485(79.9)$ & $76.7-83.1$ & $230(62.3)$ & $57.4-67.3$ & $715(73.3)$ \\
\hline Physically active † (\%)* & $163(21.4)$ & $18.5-24.4$ & $168(33.8)$ & 29.6-38.0 & $331(26.3)$ \\
\hline GGT $\geq 50 \mathrm{U} / \mathrm{L}(\%) *$ & $312(42.7)$ & $39.1-46.3$ & $128(26.2)$ & $22.3-30.1$ & $440(36.1)$ \\
\hline Metabolic syndrome † (\%) * & $199(26.2)$ & $23.1-29.3$ & $232(46.7)$ & $42.3-56.1$ & $431(34.3)$ \\
\hline Adverse MR cluster profile $+(\%) *$ & $275(40.8)$ & $37.1-44.5$ & $241(50.6)$ & $46.1-55.1$ & $516(44.9)$ \\
\hline
\end{tabular}

*significant difference of $<0.05$ between Aboriginal and TSI, using Chi square tests for categorical variables, t-test (for continuous variables with normal distribution, and Mann-Whitney rank-sum test for continuous variables with non-normal distribution $\neq$. + Abdominal obesity defined using WHO WC gender specific criteria: overweight being WC of $80-88 \mathrm{~cm}$ in females and $94-102 \mathrm{~cm}$ in males, while obesity being WC $\geq 88 \mathrm{~cm}$ in females and $102 \mathrm{~cm}$ in males. Risky drinking was defined as $>6$ drinks on any occasion or $>4$ drinks per day in males and $>4$ drinks on any occasion or $>2$ drinks per day in female in the week prior to the survey. Physically active, defined by American Heart Association criteria in which "active" means doing moderate to vigorous physical activity for more than $30 \mathrm{~min}$ per day for 5 days in the week before the survey. Metabolic syndrome defined by IDF criteria: waist circumference ( $\geq 94 \mathrm{~cm}$ in males and $\geq 80$ for females), raised triglycerides ( $\geq 1.7 \mathrm{mmol} / \mathrm{L}$ ), reduced $\mathrm{HDL}(<1.03$ in males or $<1.29$ in females), raised blood pressure (systolic $>130 \mathrm{mmHg}$ or diastolic $\geq 85$ $\mathrm{mmHg}$ ), and plasma glucose ( $\geq 5.6 \mathrm{mmol} / \mathrm{L}$ ). Adverse MR (metabolic risk) cluster profile was obtained by EM cluster analysis. WC is waist circumference, Trigs is serum triglycerides, SBP is systolic blood pressure, DBP is diastolic blood pressure, HDL is high density lipoprotein cholesterol, FPG is fasting plasma glucose.

Table 2 Demographic and health risk factor status, by GGT category in Indigenous adults

\begin{tabular}{|c|c|c|c|c|c|}
\hline & \multicolumn{2}{|c|}{ GGT<50 U/L $(n=1876)$} & \multicolumn{2}{|c|}{ GGT $\geq 50 \mathrm{U} / \mathrm{L}(\mathrm{n}=657)$} & \multirow[t]{2}{*}{$\mathrm{P}^{*}$} \\
\hline & Mean or No. & $95 \% \mathrm{Cl}$ & No. (\%) & $95 \% \mathrm{Cl}$ & \\
\hline Age (Years) (SD) & $36.6(16.3)$ & $35.8-37.3$ & $39.3(12.5)$ & $38.4-40.2$ & $<0.01$ \\
\hline Male (\%) & 779 (41.5) & $39.3-43.8$ & $440(67.0)$ & $63.4-70.6$ & $<0.01$ \\
\hline Aborigines (\%) & $1093(58.3)$ & $56.0-60.5$ & $493(75.0)$ & 71.7-78.4) & $<0.01$ \\
\hline WC (SD) & $94.3(17.2)$ & 93.5- 95.1 & $97.4(14.5)$ & $96.3-98.5$ & $<0.01$ \\
\hline Abdominal obesity $(\%) \dagger$ & & & & & 0.09 \\
\hline Normal & $655(34.9)$ & $32.8-37.1$ & $208(31.7)$ & $28.1-35.2$ & \\
\hline Overweight & $300(16.0)$ & $14.3-17.7$ & $127(19.3)$ & $16.3-22.4$ & \\
\hline Obesity & $921(49.1)$ & $46.8-51.4$ & $322(49.1)$ & $45.2-52.8$ & \\
\hline BMI (SD) & $27.5(7.2)$ & $27.2-27.9$ & $27.5(6.5)$ & $27.0-28.0$ & 0.45 \\
\hline BMI & & & & & 0.01 \\
\hline$<25$ & $760(40.5)$ & $38.3-42.7$ & $244(37.1)$ & $33.4-40.8$ & \\
\hline $25-30$ & $480(25.6)$ & $23.6-27.6$ & $207(31.5)$ & $28.0-35.1$ & \\
\hline $30+$ & $636(33.9)$ & $31.8-36.0$ & $206(31.4)$ & $27.8-34.9$ & \\
\hline SBP (SD) & $128.2(19.7)$ & $127.3-129.1$ & $135.4(18.4)$ & $134.0-136.8$ & $<0.01$ \\
\hline $\mathrm{DBP}(\mathrm{SD})$ & $69.4(13.1)$ & $68.8-70.0$ & $77.3(13.2)$ & $76.3-78.3$ & $<0.01$ \\
\hline HDL (SD) & $1.14(0.3)$ & 1.13-1.15 & $1.19(0.4)$ & $1.16-1.22$ & $<0.01$ \\
\hline Smoking (\%) & $982(52.7)$ & $50.4-55.0$ & $460(70.5)$ & $66.9-73.9$ & $<0.01$ \\
\hline Drinking (\%) & $1117(61.7)$ & $59.5-64.0$ & $565(87.7)$ & $85.2-90.3$ & $<0.01$ \\
\hline Risky drinking $+(\%) *$ & $679(60.8)$ & $57.9-6365$ & $466(82.5)$ & 79.3-85.6 & $<0.01$ \\
\hline Physically active $†$ & $467(24.9)$ & $22.9-26.9$ & $130(19.8)$ & $16.7-26.8$ & 0.01 \\
\hline FPG (SD) & $5.5(2.5)$ & $5.4-5.6$ & $6.2(2.9)$ & $5.9-6.4$ & $<0.01$ \\
\hline Diabetes (\%) & $236(12.6)$ & $11.1-14.1$ & $133(20.2)$ & $17.2-23.3$ & $<0.01$ \\
\hline Trigs (SD) $\ddagger^{*}$ & $1.5(1.1)$ & $1.4-1.52$ & $2.7(2.0)$ & $2.5-2.8$ & $<0.01$ \\
\hline Metabolic syndrome $(\%) \dagger$ & $683(36.4)$ & $34.2-38.6$ & $346(52.6)$ & $48.8-56.5$ & $<0.01$ \\
\hline Adverse MR Cluster profile (\%) † & $570(32.8)$ & 30.6-35.0 & $384(60.0)$ & $56.2-63.8$ & $<0.01$ \\
\hline
\end{tabular}

*significant difference of $<0.05$ between normal ( $<50 \mathrm{U} / \mathrm{L}$ ) and elevated ( $\geq 50 \mathrm{U} / \mathrm{L}$ ) GGT, using Chi square tests for categorical variables, t-test (for continuous variables with normal distribution, and Mann-Whitney rank-sum test for continuous variables with non-normal distributionf. $\dagger$ Abdominal obesity defined using WHO WC gender specific criteria: overweight being WC of $80-88 \mathrm{~cm}$ in females and $94-102 \mathrm{~cm}$ in males, while obesity being WC $\geq 88 \mathrm{~cm}$ in females and $102 \mathrm{~cm}$ in males. Risky drinking was defined as $>6$ drinks on any occasion or $>4$ drinks per day in males and $>4$ drinks on any occasion or $>2$ drinks per day in female in the week prior to the survey. Physically active, defined by American Heart Association criteria in which "active" means doing moderate to vigorous physical activity for more than 30 min per day for 5 days in the week before the survey. Metabolic syndrome defined by IDF criteria: waist circumference ( $\geq 94 \mathrm{~cm}$ in males and $\geq 80$ for females), raised triglycerides ( $\geq 1.7 \mathrm{mmol} / \mathrm{L})$, reduced $\mathrm{HDL}(<1.03$ in males or $<1.29$ in females), raised blood pressure (systolic $>130 \mathrm{mmHg}$ or diastolic $\geq 85 \mathrm{mmHg}$ ), and plasma glucose ( $\geq 5.6 \mathrm{mmol} / \mathrm{L}$ ). Adverse MR (metabolic risk) cluster profile was obtained by EM cluster analysis. WC is waist circumference, Trigs is serum triglycerides, SBP is systolic blood pressure, DBP is diastolic blood pressure, HDL is high density lipoprotein cholesterol, FPG is fasting plasma glucose. 
elevated GGT. The overall prevalence of elevated GGT was $25.9 \%$. In this group, people were older, more likely to be male, Aboriginal, obese, smokers, drinkers, diabetic, be classified as metabolic syndrome, have an adverse MR cluster profile, and be physically inactive, when compared to those with normal GGT.

The MR cluster profile of the population is shown in table 3 and represented in standardized units in figure 1. There were two clusters identified in this population, denoted as 'favorable', which represented $60 \%$ of the population, and 'adverse' (40\%). All metabolic variables were significantly worse and there were a significantly higher proportion of TSI people in the adverse cluster, when compared with the favorable cluster. The major contributors to cluster membership in descending order were: SBP, DBP, waist circumference, fasting glucose and triglycerides. HDL contributed little to explaining cluster membership. Together these variables explained $64 \%$ of individual allocation to each particular cluster.

Disagreement between metabolic syndrome and MR cluster membership occurred in 524 cases; 286 cases in the favorable cluster were classified as having metabolic syndrome, whereas 238 in the adverse cluster were not. Aboriginal people when compared to TSI were more likely to be in the adverse cluster but not be classified as having metabolic syndrome (Additional file 2, Tables 1 and 2).

The multiple adjusted odds of elevated GGT were significantly greater in moderate and risky drinkers compared with non-drinkers (moderate: OR 2.3 [95\%CI 1.6 - 3.2]; risky: OR 6.0 [4.4 - 8.2]), metabolic syndrome compared with no metabolic syndrome (OR 2.7 [2.1 3.5]), adverse compared with favorable MR cluster (OR

\begin{tabular}{|c|c|c|c|c|}
\hline & \multicolumn{2}{|c|}{$\begin{array}{l}\text { Favorable cluster } \\
(n=1430,60 \%)\end{array}$} & \multicolumn{2}{|c|}{$\begin{array}{l}\text { Adverse cluster } \\
(\mathrm{n}=955,40 \%)\end{array}$} \\
\hline & Mean or No. & SD & Mean or No. & SD \\
\hline Male * & 634 (44.3\%) & & $516(54.0 \%)$ & \\
\hline Aboriginal * & 912 (63.8\%) & & $543(56.9 \%)$ & \\
\hline Age (years)* & 31.8 & 13.5 & 45.6 & 14.2 \\
\hline$W C(\mathrm{~cm})^{*}$ & 89.10 & 14.76 & 104.63 & 14.48 \\
\hline Trigs $(\mathrm{mmol} / \mathrm{L}) \ddagger^{*}$ & 1.25 & 0.65 & 2.65 & 1.96 \\
\hline SBP $(\mathrm{mmHg})^{*}$ & 120.24 & 12.63 & 145.53 & 18.25 \\
\hline DBP $(\mathrm{mmHg})^{*}$ & 64.80 & 9.61 & 81.56 & 12.26 \\
\hline $\mathrm{HDL}(\mathrm{mmol} / \mathrm{L})^{*}$ & 1.19 & 0.32 & 1.09 & 0.27 \\
\hline FPG $(\mathrm{mmol} / \mathrm{L})^{*}$ & 4.73 & 0.76 & 7.23 & 2.61 \\
\hline
\end{tabular}

*significant difference of $<0.001$ between favorable and adverse MR cluster, using t-test (for continuous variables with normal distribution, and MannWhitney rank-sum test for continuous variables with non-normal distribution $\neq$ WC is waist circumference, Trigs is serum triglycerides, SBP is systolic blood pressure, DBP is diastolic blood pressure, HDL is high density lipoprotein cholesterol, FPG is fasting plasma glucose.
3.4 [2.6 - 4.3]), diabetics compared with non-diabetics (OR 2.1 [1.6 - 2.9]), and central and general overweight (central: OR 2.3 [1.6 - 3.2]; general: OR 1.7 [1.4 - 2.2]) and obesity (central: OR 3.7 [2.5 - 5.6]; general: OR 1.7 [1.3 - 2.2]), when compared to normal weight.

Ethnicity and sex stratified analyses demonstrated strong interactions between drinking and ethnicity and drinking and sex, on the odds of elevated GGT. Aboriginal drinkers were significantly more likely to have elevated GGT than TSI drinkers (OR 2.2 [1.8 - 2.8], Table 4), and male drinkers were twice as likely to have elevated GGT as female drinkers (OR 2.0 [1.2 - 3.5], Table 5). Moderate and risky alcohol drinking did not interact with ethnicity or sex on the odds of elevated GGT. There were no observed interactions between metabolic risk and either ethnicity or sex on elevated GGT.

When stratified by drinking status (Table 6), there was no evidence of a multiplicative effect of moderate or risky drinking with obesity or metabolic syndrome on elevated GGT (interaction terms not shown). However, in people with an adverse MR cluster profile, drinking alcohol at risky levels was associated with a near 3-fold increase in the log of the odds of elevated GGT when compared with non-drinkers (OR 2.8 [1.6 - 4.9]).

A post-hoc analysis was performed in order to investigate any possible interfering effects of HDL on the outcomes of the planned analysis, given that increases in both HDL (improvement) and GGT (worsening) result from increased alcohol consumption. Thus, we re-performed all steps of the above analysis, beginning with cluster analysis, excluding HDL. This process yielded two clusters of similar proportions to our previous analysis, the variable means and the proportions of Aboriginal and Torres Strait Islanders between clusters were similar to the original analysis (data not shown). Re-analysis of the individual effect of cluster membership on elevated GGT gave similar results (OR 3.5 [95\% CI 2. 9 - 4.2] compared with OR 3.4 [2.6 4.3] in the original analysis) and re-analysis of table 6 showed very similar results to those of the original analysis, even after adjustment for HDL. The overall effect of the cluster $\times$ alcohol interaction term was also similar to the original analysis (OR 1.7 [95\% CI 1.0 - 3.0]). When adjusted for HDL, the effect of the interaction term was essentially unchanged (OR 1.8 [95\% CI 1.1 - 3.2]).

\section{Discussion}

This study reported high population mean serum GGT in both men $(61.0 \pm 74.2 \mathrm{U} / \mathrm{L})$ and women $(35.0 \pm 40.4$ $\mathrm{U} / \mathrm{L})$ that exceeded the highest population mean concentrations published previously by a study in northwest Russia (Men: $43.8 \pm 60.5$ U/L; Women: $28.3 \pm 38.9$ $\mathrm{U} / \mathrm{L})$ [29]. 


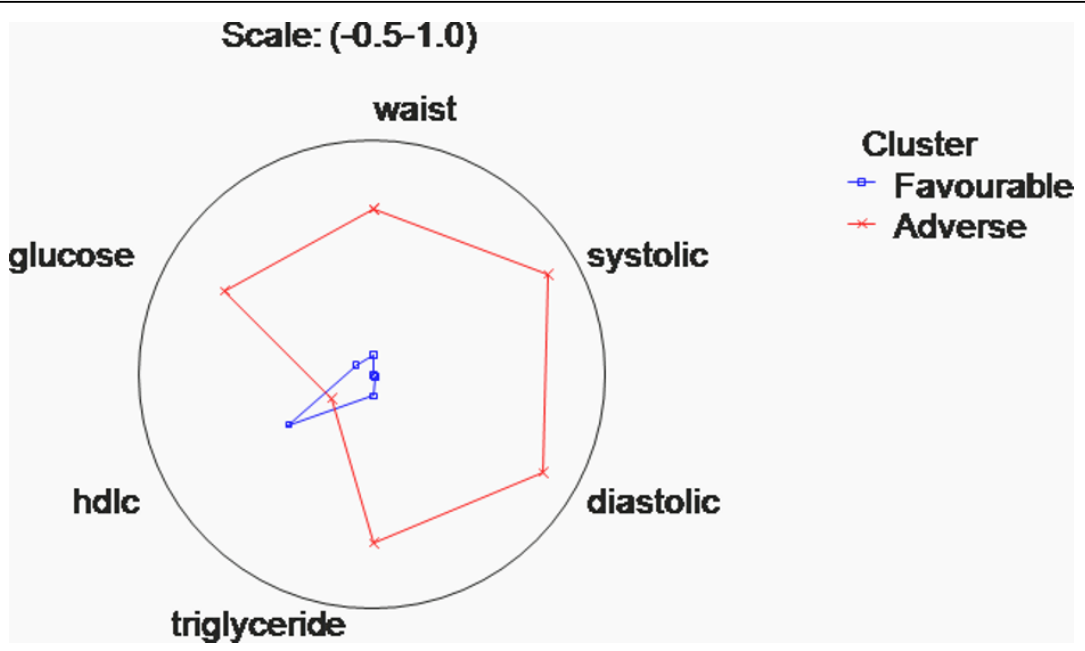

Figure 1 A standardized comparison of metabolic risk factors between distinct Indigenous population clusters. This radial/spider plot clearly shows the differences in metabolic risk factors between clusters. In the favorable compared to the adverse cluster, people have higher $\mathrm{HDL}$ levels and lower systolic and diastolic blood pressures, triglycerides, glucose and waist circumference. Data are shown in standardized units so that the magnitude of the difference between clusters can be compared between variables.

Having an adverse metabolic profile was associated with a 2.6 to 4.3 -fold increase, and metabolic syndrome with a 2.1 to 3.5 -fold increase, in the odds of having elevated GGT ( $\geq 50 \mathrm{U} / \mathrm{L})$. A similar result for metabolic syndrome has been shown within abstainers in this cohort [13]. In this Indigenous population, an adverse metabolic profile conferred 3 times the risk of elevated GGT in risky drinkers than in abstainers. Interestingly,

Table 4 Alcohol drinking and metabolic risk versus elevated GGT (GGT $\geq 50 \mathrm{U} / \mathrm{L}$ ) by ethnicity

\begin{tabular}{llll}
\hline $\begin{array}{l}\text { Aboriginal } \\
\text { Crude OR }\end{array}$ & Adj. OR* & TSI & \\
Crude OR & Adj. OR* \\
\hline
\end{tabular}

\begin{tabular}{|c|c|c|c|c|}
\hline \multicolumn{5}{|c|}{ Alcohol Drinking } \\
\hline No & 1.0 & 1.0 & 1.0 & 1.0 \\
\hline Yes & $4.9(3.6-6.7)$ & $5.6(3.9-8.0)$ & $3.3(2.1-5.1)$ & $2.2(1.3-3.7)$ \\
\hline
\end{tabular}

Alcohol risk

$\begin{array}{lllll}\text { No } & 1.0 & 1.0 & 1.0 & 1.0 \\ \text { Moderate } & 2.1(1.4-3.2) & 2.7(1.7-4.1) & 1.9(1.1-3.2) & 1.4(0.8-2.5) \\ \text { Risky } & 6.3(4.6-8.7) & 7.6(5.2-11.1) & 4.5(2.9-7.1) & 3.4(1.9-5.9)\end{array}$

Metabolic syndrome $\dagger$

$\begin{array}{lllll}\text { No } & 1.0 & 1.0 & 1.0 & 1.0 \\ \text { Yes } & 2.1(1.7-2.6) & 2.7(2.0-3.6) & 2.8(2.0-4.0) & 2.2(1.4-3.4)\end{array}$

MR cluster profile $\dagger$

\begin{tabular}{lllll} 
Favorable & 1.0 & 1.0 & 1.0 & 1.0 \\
Adverse & $3.3(2.6-4.1)$ & $3.4(2.5-4.5)$ & $3.9(2.7-5.7)$ & $3.2(2.0-5.0)$ \\
\hline
\end{tabular}

* Adjusted for age, sex, ethnicity, BMI, smoking, and PA level. † Risky drinking was defined as $>6$ drinks on any occasion or $>4$ drinks per day in males and $>4$ drinks on any occasion or $>2$ drinks per day in female in the week prior to the survey. Metabolic syndrome defined by IDF criteria: waist circumference ( $\geq 94 \mathrm{~cm}$ in males and $\geq 80$ for females), raised triglycerides $(\geq 1.7 \mathrm{mmol} / \mathrm{L})$, reduced $\mathrm{HDL}(<1.03$ in males or $<1.29$ in females), raised blood pressure (systolic $>130 \mathrm{mmHg}$ or diastolic $\geq 85 \mathrm{mmHg}$ ), and plasma glucose ( $\geq 5.6$ $\mathrm{mmol} / \mathrm{L}$ ). Adverse MR (metabolic risk) cluster profile was obtained by EM cluster analysis. this finding did not hold when using the metabolic syndrome classification in place of the MR cluster. Previous studies in moderate alcohol drinkers and abstainers have claimed additive effects of alcohol consumption and BMI on elevated serum GGT and ALT $[14,15]$, but an interactive effect modeled using logistic regression was not evident in this Australian indigenous population.

Table 5 Alcohol drinking and metabolic risk versus elevated GGT (GGT $\geq 50 \mathrm{U} / \mathrm{L}$ ) by gender

\begin{tabular}{rrll}
\hline $\begin{array}{l}\text { Female } \\
\text { Crude OR }\end{array}$ & Adj. OR* & $\begin{array}{l}\text { Male } \\
\text { Crude OR }\end{array}$ & Adj. OR* \\
\hline Alcohol drinking & & &
\end{tabular}

$\begin{array}{lllll}\text { No } & 1.0 & 1.0 & 1.0 & 1.0 \\ \text { Yes } & 2.7(1.9-3.8) & 3.5(2.3-5.2) & 5.4(3.6-8.0) & 5.9(4.0-9.9)\end{array}$

Alcohol risk

$\begin{array}{lllll}\text { No } & 1.0 & 1.0 & 1.0 & 1.0 \\ \text { Moderate } & 1.0(0.6-1.9) & 1.5(0.9-2.6) & 2.8(1.8-4.5) & 3.5(2.1-5.9) \\ \text { Risky } & 4.1(2.9-5.8) & 5.2(3.4-8.0) & 6.7(4.4-10.0) & 8.5(5.3-13.5) \\ \text { Metabolic syndrome } \dagger & & & \\ \text { No } & 1.0 & 1.0 & 1.0 & 1.0 \\ \text { Yes } & 2.7(2.0-3.7) & 3.1(2.2-4.5) & 2.1(1.6-2.6) & 1.8(1.3-2.5)\end{array}$

MR cluster profile $\dagger$

\begin{tabular}{lllll} 
Favorable & 1.0 & 1.0 & 1.0 & 1.0 \\
Adverse & $2.9(2.1-3.9)$ & $3.2(2.2-4.7)$ & $3.0(2.3-3.8)$ & $3.2(2.3-4.4)$ \\
\hline
\end{tabular}

* Adjusted for age, ethnicity, BMl, smoking, and PA level. † Risky drinking was defined as $>6$ drinks on any occasion or $>4$ drinks per day in males and $>4$ drinks on any occasion or $>2$ drinks per day in female in the week prior to the survey. Metabolic syndrome defined by IDF criteria: waist circumference ( $\geq 94 \mathrm{~cm}$ in males and $\geq 80$ for females), raised triglycerides $(\geq 1.7 \mathrm{mmol} / \mathrm{L}$ ), reduced $\mathrm{HDL}(<1.03$ in males or $<1.29$ in females), raised blood pressure (systolic $>130 \mathrm{mmHg}$ or diastolic $\geq 85 \mathrm{mmHg}$ ), and plasma glucose ( $\geq 5.6$ $\mathrm{mmol} / \mathrm{L}$ ). Adverse MR (metabolic risk) cluster profile was obtained by EM cluster analysis. 
Table 6 Risk of elevated GGT with obesity, metabolic syndrome and metabolic risk cluster by drinking status

\begin{tabular}{|c|c|c|c|c|c|c|}
\hline & \multicolumn{2}{|c|}{ Non-drinkers $(n=791)$} & \multicolumn{2}{|c|}{ Moderate drinkers $(n=552)$} & \multicolumn{2}{|c|}{ Risky Drinkers $+(n=1183)$} \\
\hline & Crude OR & Adj. $O R^{*}$ & Crude OR & Adj. OR* & Crude OR & Adj. $O R^{*}$ \\
\hline \multicolumn{7}{|c|}{ Abdominal Obesity $†$} \\
\hline Normal & 1.0 & 1.0 & 1.0 & 1.0 & 1.0 & 1.0 \\
\hline Overweight & $1.4(0.6-3.5)$ & $1.5(0.6-3.9)$ & $1.5(0.8-2.9)$ & $1.9(0.9-3.8)$ & $1.8(1.3-2.5)$ & $3.2(2.2-4.7)$ \\
\hline Obese & $2.0(1.0-4.0)$ & $2.6(1.1-5.7)$ & $1.7(1.03-2.9)$ & $4.5(2.3-8.6)$ & $1.5(1.2-1.9)$ & $4.2(2.9-5.9)$ \\
\hline \multicolumn{7}{|l|}{ BMI } \\
\hline$<25$ & 1.0 & 1.0 & 1.0 & 1.0 & 1.0 & 1.0 \\
\hline $25-30$ & $2.0(1.1-3.8)$ & $2.0(1.01-3.9)$ & $2.1(1.2-3.6)$ & $3.0(1.6-5.6)$ & $1.5(1.2-2.0)$ & $2.4(1.7-3.3)$ \\
\hline $30+$ & $1.5(0.8-2.8)$ & $1.8(0.9-3.6)$ & $1.6(0.9-2.8)$ & $2.7(1.4-5.2)$ & $1.4(1.0-1.8)$ & $2.9(2.1-4.1)$ \\
\hline \multicolumn{7}{|c|}{ Metabolic syndrome $\dagger$} \\
\hline No & 1.0 & 1.0 & 1.0 & 1.0 & 1.0 & 1.0 \\
\hline Yes & $2.3(1.4-3.8)$ & $2.4(1.3-4.1)$ & $2.5(1.6-3.9)$ & $2.8(1.7-4.6)$ & $2.8(2.2-3.5)$ & $3.7(2.8-5.0)$ \\
\hline \multicolumn{7}{|c|}{ MR Cluster profilet } \\
\hline Favorable & 1.0 & 1.0 & 1.0 & 1.0 & 1.0 & 1.0 \\
\hline Adverse & $1.9(1.2-3.1)$ & $1.6(0.9-2.8)$ & $3.0(1.9-4.8)$ & $2.8(1.6-4.9)$ & $5.1(3.9-6.6)$ & $4.9(3.7-6.7)$ \\
\hline
\end{tabular}

*Adjusted by age, sex, and ethnicity, smoking, and PA level. $\dagger$ Risky drinking was defined as $>6$ drinks on any occasion or $>4$ drinks per day in males and $>4$ drinks on any occasion or $>2$ drinks per day in female in the week prior to the survey. Abdominal obesity defined using WHO WC gender specific criteria: overweight being WC of $80-88 \mathrm{~cm}$ in females and $94-102 \mathrm{~cm}$ in males, while obesity being WC $\geq 88 \mathrm{~cm}$ in females and $102 \mathrm{~cm}$ in males. Metabolic syndrome defined by IDF criteria: waist circumference ( $\geq 94 \mathrm{~cm}$ in males and $\geq 80$ for females), raised triglycerides $(\geq 1.7 \mathrm{mmol} / \mathrm{L})$, reduced $\mathrm{HDL}(<1.03$ in males or $<1.29$ in females), raised blood pressure (systolic $>130 \mathrm{mmHg}$ or diastolic $\geq 85 \mathrm{mmHg}$ ), and plasma glucose ( $\geq 5.6 \mathrm{mmol} / \mathrm{L}$ ). Adverse MR (metabolic risk) cluster profile was obtained by EM cluster analysis.

These findings are novel and are significant in this population. Although there are well known interactions between BMI and drinking on GGT, to the authors knowledge no published data exist regarding the interaction between multiple co-existing metabolic risk factors or different metabolic endophenotypes and alcohol intake on liver enzymes. This is important as the interactions may be much more severe for people with cardio-metabolic risk factors over and above overweight/ obesity. Moreover, we have tested the interactions with two different methods for classifying cardio-metabolic risk: (1) the IDF metabolic syndrome definition; (2) a data driven approach to defining population metabolic endophenotypes using the same variables. This departure from the controversial dichotomous classification of the metabolic syndrome in capturing the population distribution of multiple metabolic risk factors is a major strength of this study. A priori, we conceived that internationally used clinical cut-points for metabolic syndrome classification may not apply equally to Australian Aboriginal and Torres Strait Islander peoples as there metabolic endophenotypes are quite different (as evidenced in this cohort by Table 1) and thus the relations between cardio-metabolic risk factors may vary. We indeed demonstrated that there was a discrepancy $(\mathrm{n}=$ 524 cases) between clinical metabolic syndrome classification and metabolic endophenotypes (clusters) that differed by ethnicity. Aboriginals were more likely to be classified as not having metabolic syndrome but being in the adverse MR cluster compared with Torres Strait Islanders who were more likely to be classified as metabolic syndrome but be in the favourable MR cluster. This could be partially due to inappropriate waist circumference cut-offs causing misclassification of IDF metabolic syndrome which may in turn partly explain the lack of interaction of alcohol drinking with metabolic syndrome and obesity on elevated GGT. MR clusters differed in their ethnic distribution, and cluster membership was mostly explained by blood pressure rather than abdominal obesity, which tends to explain clustering in Caucasian populations. These different metabolic (endo)phenotypes and their risk to future health outcomes are deserving of further study. The interactions of metabolic profile or body fat with alcohol consumption on serum GGT may be dependent on gene polymorphisms in the population that affect the level of fat accumulation in liver cells, oxidative stress, cytokine production, immune response and tissue fibrosis [30]. However, at present no genetic associations with advanced NAFLD have been confirmed [31].

This is the first study of the associations of alcohol intake and metabolic risk, their combined influence and the potentially modifying role of gender and ethnic background on elevated serum GGT in Indigenous Australians. Although we have only studied an intermediate outcome of liver function (GGT), to date very little has been published on biochemical liver dysfunction or NAFLD in Indigenous populations worldwide. The prevalence of elevated GGT in the communities studied (overall 25.9\%: males $36.1 \%$, females $16.5 \%$ ) were comparable to those reported in the Russian study. Similarly, in an Atayal Aboriginal community in Taiwan, the 
overall prevalence of elevated GGT (defined in this study as $\geq 61 \mathrm{U} / \mathrm{L}$ ) was $22.4 \%$ (males $34.9 \%$, females $10.7 \%)$. Over two thirds of this population were Aboriginal and had an elevated GGT prevalence of $28.6 \%$ compared with $8.8 \%$ in non-aboriginals [32]. It has been suggested that the high prevalence of type 2 diabetes in North American indigenous populations may indicate a high prevalence of NAFLD [33], and despite a lack of published data, this may also be true in Indigenous Australians. Elevated serum GGT and diagnosed NAFLD have also been shown to predict incident cardiovascular events in the general population [34], and more strongly in diabetics [34,35] and alcohol drinkers [34].

Almost $80 \%$ of Indigenous males and 59\% of Indigenous females in this study reported that they currently drink alcohol. These percentages appear higher than Australian population estimates for Indigenous Australians generally [36] and reflects near universal access to alcohol from "wet" canteens in these remote communities in far north Queensland at the time of the study. In these communities, drinking alcohol was associated with a 3.6 to 6.2 -fold increase in the chance of having elevated GGT after adjustment for age, gender and ethnicity and the effect increased from moderate to risky alcohol consumption. The association between alcohol intake and GGT is well described [11] with modifications of this association by sex [37], ethnicity [38-40] and age [41]. In these communities, the observed doubling in risk of elevated GGT from drinking in males compared with females, and in Aboriginal compared with TSI peoples was directly related to the prevalence of high risk alcohol consumption by males compared with females and Aboriginal compared with TSI people. Thus, irrespective of sex or ethnicity, people who drink alcohol at risky levels have equivalent odds of elevated GGT.

Limitations to this study include a possible downward response bias to 7-day recall of alcohol consumption [42], the sole use of GGT as an outcome and indicator of NAFLD due to the limited ability to perform more advanced investigations in very remote communities, and a small degree of missing data on major exposure variables that differentially occurred in participants who were female, older and had lower blood pressure.

\section{Conclusions}

Taken together, drinking was most strongly associated with elevated GGT in a dose dependent manner. Aboriginal men were at particularly high risk of elevated GGT from drinking, due largely to the high prevalence of risky drinking in this group. In this Indigenous population, an adverse metabolic profile conferred 3 times the risk of elevated GGT in risky drinkers than in abstainers, independent of sex and ethnicity.
Interventions need to target modifiable community determinants of both the population's metabolic risk status and risky alcohol drinking behaviour to achieve greater reduction in population GGT levels. The effects of such strategies on the rates of new diabetes, CHD and stroke cases (major contributors to the Indigenous health gap in Australia) require further investigation.

\section{Additional material}

Additional file 1: Expectation Maximisation Cluster analysis and Partial Least Squares expanded methods. This file contains an expanded discussion of the EM cluster and PLS analysis methods.

Additional file 2: Disagreement between IDF metabolic syndrome classification and MR cluster membership. This file contains two tables that show (1) the level of disagreement between the metabolic syndrome classification and MR cluster membership, and (2) the demographic and metabolic characteristics of cases in which disagreement occurred.

\section{Acknowledgements}

Kerry Arabena, Phillip Mills, Dympna Leonard and the Indigenous Health Workers contributed to various aspects of the work including study design and acquisition of data but have not qualified for authorship. Thank you to the participants in the community surveys.

This work was support by the National Health and Medical Research Council of Australia (NH\&MRC) [grant number 278402] to R.A.M. M.T.H is supported by an NH\&MRC Training Fellowship (Public Health) [grant number 511345].

\section{Author details}

${ }^{1}$ Spencer Gulf Rural Health School (SGRHS), University of South Australia and The University of Adelaide, Whyalla Norrie SA, Australia. ${ }^{2}$ Centre for Rural Health and Community Development (CRHaCD), University of South Australia, Whyalla Norrie SA, Australia. ${ }^{3}$ Sansom Institute, Division of Health Sciences, University of South Australia, Adelaide SA, Australia. ${ }^{4}$ Applied Statistics Unit, Centre for Regional Engagement, University of South Australia, Mount Gambier SA, Australia.

\section{Authors' contributions}

MTH contributed to the analysis and interpretation of data, drafting of the manuscript and critical revision of the manuscript for important intellectual content and data analysis. ML performed the data analysis and contributed to interpretation of data, drafting of the manuscript, critical revision of the manuscript for important intellectual content. JP performed data analysis and contributed to interpretation of data, drafting and critical revision of the manuscript for important intellectual content. RAM was involved in the conception and design of the study, acquisition of data, interpretation of data and critical revision of the manuscript for important intellectual content and for obtaining funding and administrative, technical and material support. ML had full access to all of the data in the study and takes responsibility for the integrity of the data and the accuracy of the data analysis. All authors read and approved the final manuscript.

\section{Competing interests}

The authors declare that they have no competing interests.

Received: 15 March 2010 Accepted: 3 August 2010

Published: 3 August 2010

\section{References}

1. Moreno-Sanchez D: [Epidemiology and natural history of primary nonalcoholic fatty liver disease]. Gastroenterol Hepatol 2006, 29(4):244-254.

2. Tahan V, Canbakan B, Balci H, Dane F, Akin H, Can G, Hatemi I, Olgac V, Sonsuz A, Ozbay G, et al: Serum gamma-glutamyltranspeptidase 
distinguishes non-alcoholic fatty liver disease at high risk. Hepatogastroenterology 2008, 55(85):1433-1438.

3. Fraser A, Harris R, Sattar N, Ebrahim S, Smith GD, Lawlor DA: Alanine aminotransferase, gamma glutamyltransferase and incident diabetes: The British Women's Heart and Health Study and meta-analysis. Diabetes Care 2009, 32(4):741-51.

4. Fraser A, Harris R, Sattar N, Ebrahim S, Smith GD, Lawlor DA: Gammaglutamyltransferase is associated with incident vascular events independently of alcohol intake: analysis of the British Women's Heart and Health Study and Meta-Analysis. Arterioscler Thromb Vasc Biol 2007, 27(12):2729-2735.

5. Leonard D, McDermott R, Odea K, Rowley KG, Pensio P, Sambo E, Twist A, Toolis R, Lowson S, Best JD: Obesity, diabetes and associated cardiovascular risk factors among Torres Strait Islander people. Aust N Z J Public Health 2002, 26(2):144-149.

6. Daniel M, Rowley KG, McDermott R, O'Dea K: Diabetes and impaired glucose tolerance in Aboriginal Australians: prevalence and risk. Diabetes Res Clin Pract 2002, 57(1):23-33.

7. Schutte AE, Shemesh T, Rowley K, Best JD, McDermott R, O'Dea K: The metabolic syndrome and changing relationship between blood pressure and insulin with age, as observed in Aboriginal and Torres Strait Islander peoples. Diabet Med 2005, 22(11):1589-1597.

8. Daniel M, Rowley KG, McDermott R, Mylvaganam A, O'Dea K: Diabetes incidence in an Australian aboriginal population. An 8-year follow-up study. Diabetes Care 1999, 22(12):1993-1998.

9. McDermott RA, McCulloch BG, Campbell SK, Young DM: Diabetes in the Torres Strait Islands of Australia: better clinical systems but significant increase in weight and other risk conditions among adults, 1999-2005. Med J Aust 2007, 186(10):505-508.

10. Vos T, Barker B, Begg S, Stanley L, Lopez AD: Burden of disease and injury in Aboriginal and Torres Strait Islander Peoples: the Indigenous health gap. Int J Epidemiol 2009, 38(2):470-7.

11. Alatalo P, Koivisto H, Puukka K, Hietala J, Anttila P, Bloigu R, Niemela O: Biomarkers of Liver Status in Heavy Drinkers, Moderate Drinkers and Abstainers. Alcohol Alcohol 2009, 44(2):199-203.

12. Suter PM: Is alcohol consumption a risk factor for weight gain and obesity? Crit Rev Clin Lab Sci 2005, 42(3):197-227.

13. Li M, Campbell S, McDermott R: gamma-Glutamyltransferase, Obesity, Physical Activity, and the Metabolic Syndrome in Indigenous Australian Adults. Obesity (Silver Spring) 2009, 17(4):809-13.

14. Alatalo PI, Koivisto HM, Hietala JP, Puukka KS, Bloigu R, Niemela OJ: Effect of moderate alcohol consumption on liver enzymes increases with increasing body mass index. Am J Clin Nutr 2008, 88(4):1097-1103.

15. Puukka K, Hietala J, Koivisto H, Anttila P, Bloigu R, Niemela O: Additive effects of moderate drinking and obesity on serum gamma-glutamyl transferase activity. Am J Clin Nutr 2006, 83(6):1351-1354, quiz 1448-1359.

16. Wang $Z$, Hoy WE: Is the Framingham coronary heart disease absolute risk function applicable to Aboriginal people? Med J Aust 2005, 182(2):66-69.

17. Cappuccio FP, Oakeshott P, Strazzullo P, Kerry SM: Application of Framingham risk estimates to ethnic minorities in United Kingdom and implications for primary prevention of heart disease in general practice: cross sectional population based study. Bmj 2002, 325(7375):1271.

18. Empana JP, Ducimetiere P, Arveiler D, Ferrieres J, Evans A, Ruidavets JB, Haas B, Yarnell J, Bingham A, Amouyel P, et al: Are the Framingham and PROCAM coronary heart disease risk functions applicable to different European populations? The PRIME Study. Eur Heart J 2003, 24(21):1903-1911.

19. D'Agostino RB, Grundy S, Sullivan LM, Wilson P: Validation of the Framingham coronary heart disease prediction scores: results of a multiple ethnic groups investigation. Jama 2001, 286(2):180-187.

20. O'Dea K, Rowley KG: Macrovascular disease risk factors and insulin resistance in Aboriginal and Torres Strait Islander people. J Diabetes Complications 2002, 16(1):9-16.

21. McDermott RA, Tulip F, Schmidt B: Diabetes care in remote northern Australian Indigenous communities. Med J Aust 2004, 180(10):512-516.

22. Miller G, McDermott R, McCulloch B, Leonard D, Arabena K, Muller R: The Well Person's Health Check: a population screening program in indigenous communities in north Queensland. Aust Health Rev 2002, 25(6):136-147.

23. Australian Bureau of Statistics: 2001 Census Dictionary Canberra: Australian Bureau of Statistics 2001.
24. Haskell WL, Lee IM, Pate RR, Powell KE, Blair SN, Franklin BA, Macera CA, Heath GW, Thompson PD, Bauman A: Physical activity and public health: updated recommendation for adults from the American College of Sports Medicine and the American Heart Association. Med Sci Sports Exerc 2007, 39(8):1423-1434

25. National Health and Medical Research Council: Australian Alcohol Guidelines: Health Risks and Benefits. Canberra: National Health and Medical Research Council 2001.

26. Alberti KG, Zimmet $P$, Shaw J: The metabolic syndrome-a new worldwide definition. Lancet 2005, 366(9491):1059-1062.

27. World Health Organisation: Obesity: preventing and managing the global epidemic: report of a WHO consultation on obesity, Geneva, 3-5 June, 1997 Geneva: World Health Organisation 1998.

28. Alberti KG, Zimmet PZ: Definition, diagnosis and classification of diabetes mellitus and its complications. Part 1: diagnosis and classification of diabetes mellitus provisional report of a WHO consultation. Diabet Med 1998, 15(7):539-553.

29. Nilssen O, Averina M, Brenn T, Brox J, Kalinin A, Archipovski V: Alcohol consumption and its relation to risk factors for cardiovascular disease in the north-west of Russia: the Arkhangelsk study. Int J Epidemiol 2005, 34(4):781-788.

30. Wilfred de Alwis NM, Day CP: Genetics of alcoholic liver disease and nonalcoholic fatty liver disease. Semin Liver Dis 2007, 27(1):44-54

31. Wilfred de Alwis NM, Day CP: Genes and nonalcoholic fatty liver disease. Curr Diab Rep 2008, 8(2):156-163.

32. Lin CF, Shiau TJ, Ko YC, Chen PH, Wang JD: Prevalence and determinants of biochemical dysfunction of the liver in Atayal Aboriginal community of Taiwan: is betel nut chewing a risk factor? BMC Gastroenterol 2008, 8:13.

33. Scott JD, Garland N: Chronic liver disease in Aboriginal North Americans. World J Gastroenterol 2008, 14(29):4607-4615.

34. Lee DH, Silventoinen $\mathrm{K}, \mathrm{Hu} G$, Jacobs DR Jr, Jousilahti P, Sundvall J, Tuomilehto J: Serum gamma-glutamyltransferase predicts non-fatal myocardial infarction and fatal coronary heart disease among 28,838 middle-aged men and women. Eur Heart J 2006, 27(18):2170-2176.

35. Targher G, Bertolini L, Rodella S, Tessari R, Zenari L, Lippi G, Arcaro G: Nonalcoholic fatty liver disease is independently associated with an increased incidence of cardiovascular events in type 2 diabetic patients. Diabetes Care 2007, 30(8):2119-2121

36. Trewin D, Madden R: The Health and Welfare of Australia's Aboriginal and Torres Strait Islander Peoples 2005. Canberra: Australian Institute of Health and Welfare and Australian Bureau of Statistics 2005

37. Stranges $S$, Freudenheim JL, Muti P, Farinaro E, Russell M, Nochajski TH, Trevisan M: Differential effects of alcohol drinking pattern on liver enzymes in men and women. Alcohol Clin Exp Res 2004, 28(6):949-956.

38. Stranges S, Freudenheim JL, Muti P, Farinaro E, Russell M, Nochajski TH, Trevisan M: Greater hepatic vulnerability after alcohol intake in African Americans compared with Caucasians: a population-based study. J Natl Med Assoc 2004, 96(9):1185-1192.

39. Stewart SH, Connors GJ: Ethnicity, alcohol drinking and changes in transaminase activity among heavy drinkers. J Natl Med Assoc 2007, 99(5):564-569.

40. Stewart SH: Racial and ethnic differences in alcohol-associated aspartate aminotransferase and gamma-glutamyltransferase elevation. Arch Intern Med 2002, 162(19):2236-2239.

41. Puukka K, Hietala J, Koivisto H, Anttila P, Bloigu R, Niemela O: Age-related changes on serum ggt activity and the assessment of ethanol intake. Alcohol Alcohol 2006, 41(5):522-527.

42. Greenfield TK, Kerr WC: Alcohol measurement methodology in epidemiology: recent advances and opportunities. Addiction 2008, 103(7):1082-1099.

Pre-publication history

The pre-publication history for this paper can be accessed here: http://www.biomedcentral.com/1471-2458/10/454/prepub

doi:10.1186/1471-2458-10-454

Cite this article as: Haren et al: Alcohol, metabolic risk and elevated serum gamma-glutamyl transferase (GGT) in Indigenous Australians. BMC Public Health 2010 10:454. 